\title{
Pyrolysis Characterization of a Linear Low Density Polyethylene
}

\author{
JORGE CAPOTE, DANIEL ALVEAR, ORLANDO ABREU, MARIANO LAZARO, and EDUARDO \\ PUENTE \\ GIDAI group. Transports - Technology Projects and Processes Department \\ University of Cantabria \\ Los Castros Avn. 39005 Santander, Spain
}

\begin{abstract}
A set of parameters for pyrolysis characterization of linear low density polyethylene (LLDPE) were chosen to measure its combustion behaviour. Two kinds of parameters were selected, material and reaction. The material parameters were: effective values of the mass density $(\rho)$; specific heat capacity $(c)$; thermal conductivity $(k)$; absorption coefficient $(\xi)$ and emissivity $(\varepsilon)$. The reaction parameters were the exponential factor $(Z)$, the energy of activation $(E)$ and the reaction mechanism $f(\alpha)$. In addition simultaneous thermal analysis (STA) tests were carried out at heating rates of 2,5 and $10 \mathrm{~K} / \mathrm{min}$ in $\mathrm{N}_{2}$ atmosphere to obtain the kinetic triplet and cone calorimeter tests at irradiance levels of $25,40,50$ and $75 \mathrm{~kW} / \mathrm{m}^{2}$ to compare the simulated mass loss rate against real mass loss rate. Finally the cone calorimeter tests were used as input values to optimize the parameter set to perform real mass loss rate.
\end{abstract}

KEYWORDS: kinetic, pyrolysis, evolutionary algorithms, cone calorimeter, polyethylene.

\section{INTRODUCTION}

It is recognized that the fire engineering methods have developed rapidly during the last decade enabling a better understanding of important subjects of the fire performance of materials (pyrolysis, combustion, etc.). These studies have used different characterization tests, such as thermogravimetric analysis (differential scanning calorimetry (DSC) and thermogravimetric analysis (TGA)) and calorimetry, based on the measurement of the heat release rate (HRR) of materials under well controlled experimental conditions (cone calorimeter, fire propagation apparatus (FPA), mass loss calorimeter (MLC) and furniture calorimeter.

Modelling the phenomenon of pyrolysis as it is defined in ISO 13943 and ASTM-E176 has been treated in fire safety science and engineering literature, via a variety of approaches. A range of empirical formulations based on experimental data obtained from the cone calorimeter or furniture calorimeter tests, to semiempirical models [1-3] that consider transient heat conduction, to comprehensive models [4,5] based on advanced descriptions of the in-solid heat and mass transfer processes, have been developed. Comprehensive pyrolysis models adopt a material science perspective, and describe the heat-driven physical-chemical transformation of the virgin solid into solid, liquid and gaseous products. While these models have the ability to capture the influence of the gas-to-solid thermal loading on the rate of production of flammable vapors (i.e. on the fuel mass loss rate), they typically include a large number of unknown parameters that require optimization (calibration).

The intended outcome of this research is to present an experimental methodology for obtaining the reaction parameters followed by an approach for estimating a narrow range of values for the optimization process using evolutionary algorithms. This will add to the portfolio of validation exercises already in existence and help improve the use of computer models for predicting behaviour of fires, and thus highlight whether there is a need to further clarify if the real properties are directly usable as inputs for these kind of models $[4,5]$.

During this research a one-dimensional numerical model of burning was used to simulate cone calorimeter tests [6] performed on a linear low density polyethylene (LLDPE). Along with the computational pyrolysis model called 'Gpyro' (version 0.700 for windows) developed by Lautenberger at Berkeley University [5]. In Gpyro, the material is defined through a set of parameters that can be optimized by an evolutionary algorithm implemented within the computational model. The research aimed to model material performance under fire conditions close to the real performance. The criterion chosen to compare real and simulated values was the mass loss rate (MLR). 
Unknown model parameters include material properties (e.g. effective values of the mass density $(\rho)$, specific heat capacity $(c)$, thermal conductivity $(k)$, absorption coefficient $(k)$ and emissivity $(\varepsilon)$ ) and parameters of the kinetics of chemical reactions (e.g. set of kinetic triplet). The experimental data comes from cone calorimeter tests [6] (the cone calorimeter is a well-established, relatively well-controlled, quasione-dimensional configuration) and provides information on the temporal variations of the fuel mass loss rate for different levels of radiant exposure. The material was a linear low density polyethylene.

\section{MODEL AND METHODS}

\section{Gpyro Model}

The following text does not aim to give a comprehensive description of the model, but to describe the model features that have been used in characterization process. The reader is referred to Ref. [5] for more detailed information.

Heterogeneous reaction stoichiometry gives:

$$
A_{k}+\sum_{j=1}^{N} v_{j, k}^{\prime} \text { gas } j \rightarrow v_{B, k} B_{k}+\sum_{j=1}^{N} v_{j, k}^{\prime \prime} \text { gas } j
$$

A particular condensed phase reaction is denoted by the index $k$, and the total number of condensed phase reactions is designated as $K$. The stoichiometry of gas phase reactions is expressed using the stoichiometric coefficients $(v)$ on a mass basis. $A_{k}$ denotes the condensed phase reactant species (the condensed phase species consumed by reaction $k$ ) and $B_{k}$ denotes the condensed phase product species (the condensed phase species generated by reaction $k$ ). The composition of the gases consumed and produced by an heterogeneous reaction is controlled by the mass yield parameters $v_{j, k}^{\prime}$ and $v_{j, k}^{\prime \prime} \cdot \mathrm{v}_{1, \pi}^{\pi}$

Heterogeneous reaction kinetics gives:

$r_{k}=f\left(\alpha_{A_{k}}\right) \frac{\left(\bar{\rho} Y_{A_{k}} \Delta z\right)_{\Sigma}}{\Delta z} Z_{k} \exp \left(-\frac{E_{k}}{R T}\right) g\left(Y_{\mathrm{O}_{2}}\right) H\left(T-T_{c r i t, k}\right)$

Here, $f\left(\alpha_{A_{k}}\right)$ is the reaction model. $H\left(T-T_{\text {crit }, k}\right)$ is the Heaviside step function ( 0 for $T-T_{\text {crit }, k}<0$, and 1 for $\left.T-T_{\text {crit, } k} \geq 0\right)$. This effectively forces the reaction rate to be zero below $T_{c r i t, k}$. The $k^{\text {th }}$ reaction rate $\left(r_{k}\right)$ is the destruction rate of condensed phase species $A_{k}$ by condensed phase reaction $k$. For each reaction $k$, the index of the condensed phase reactant species $\left(A_{k}\right)$ and the index of the condensed phase product species $\left(B_{k}\right)$ are specified by the user. The function $g\left(Y_{\mathrm{O}_{2}}\right)$ models the influence of $\mathrm{O}_{2}$. The $\bar{\rho} Y_{A_{k}}$ is the density of condensed phase species $A$ under $k$ reaction process. $\Delta z$ is the grid cell. The $\Sigma$ subscript means that the initial density of species $k$ at that moment $(t)$ is a sum of initial density at $t_{0}$ plus the mass formed by other reactions (numerical integration).

\section{Simultaneous Thermal Analysis}

A Netzsch STA 449 F3 was used to study both the kinetic parameters and the enthalpies of LLDPE decomposition. The mass of the samples were in the range of $8-10 \times 10^{-6} \mathrm{~kg}$. The complete process of sample heating was from $303 \mathrm{~K}$ to $873 \mathrm{~K}$ at rates $(\beta)$ of $3.33 \times 10^{-2} \mathrm{~K} \cdot \mathrm{s}^{-1}, 8.33 \times 10^{-2} \mathrm{~K} \cdot \mathrm{s}^{-1}$ and $1.67 \times 10^{-1} \mathrm{~K} \cdot \mathrm{s}^{-1}$.

The tests were conducted in a nitrogen atmosphere. The sample holder within the platinum oven was purged with $10^{-6} \mathrm{~m}^{3} \cdot \mathrm{s}^{-1}$ of pure nitrogen. Alumina crucibles were used. 


\section{Cone Calorimeter Tests}

The MLR of burning LLDPE was measured using the Fire Testing Technology Ltd cone calorimeter. The configuration of tests was performed according to the standard [6]. The samples were mounted in the horizontal position with an edge frame. A mesh was placed on top of the sample to minimize the effect of intumescing. The bottom of the holder was filled with a refractory ceramic material as per the standard [6]. The samples were wrapped with aluminum foil. The MLR was measured by a load cell with an accuracy of $10^{-4} \mathrm{~kg}$.

Twelve samples with a surface area measuring $0.1 \times 0.1 \mathrm{~m}$ and a mean thickness of $0.005 \mathrm{~m}$ were tested at irradiance levels of $25 \mathrm{~kW} / \mathrm{m}^{2}, 40 \mathrm{~kW} / \mathrm{m}^{2}, 50 \mathrm{~kW} / \mathrm{m}^{2}$ and $75 \mathrm{~kW} / \mathrm{m}^{2}$. The accuracy of irradiance levels was $2 \mathrm{~kW} / \mathrm{m}^{2}$.

\section{Material}

The LLDPE was ExxonMobil ${ }^{\mathrm{TM}}$ LLDPE LL 4004EL. The slabs $(0.1 \times 0.1 \times 0.005 \mathrm{~m})$ were made by a compression molding process at $423 \mathrm{~K}$ for $3 \mathrm{~min}$. The density of manufactured LLDPE was $924 \mathrm{~kg} / \mathrm{m}^{3}$, but after the molding process, the mean value measured at laboratory $\left(25^{\circ} \mathrm{C}\right.$ and $\mathrm{RH}$ of $\left.45 \%\right)$ was $948.5 \mathrm{~kg} / \mathrm{m}^{3}$. The peak of melting point was $395 \mathrm{~K}$.

\section{PARAMETERIZATION AND RESULTS}

\section{General Model Parameterization}

For the computational tests it was assumed that solids can undergo simultaneous reactions according to a number of assumptions. These assumptions are:

- An instantaneous release of volatiles from solid to the gas phase. The vapors instantaneously escape with no flow resistance. The general parameter GASES_PRODUCED_AT_SOLID was set .FALSE.

- Local thermal equilibrium between the solid and the volatiles. The general parameter THERMAL_EQUILIBRIUM was set.TRUE.

- No condensation of gaseous products. In Gpyro, this type of reaction is invoked by setting $\chi=1 . \chi$ is the fraction of the bulk density difference between condensed phase species A and $\mathrm{B}$ that is converted to gases. A value of 1 means that the density difference due to the production of a lower density solid $\left(\rho_{B}\right)$ from a higher density solid $\left(\rho_{A}\right)$ will result in the production of gases.

- No porosity effects. The general parameter SOLVE_POROSITY was set .FALSE.

In addition permeability effects in Gpyro are ignored, thus ensuring the pressure solver is not invoked. All properties are assumed to be independent of temperature. For the case considered in this research, $T_{\text {crit }}=0$, and for a reaction not sensitive to oxygen $\left(n_{\mathrm{O} 2}=0\right)$, the reaction equation is:

$r_{k}=f\left(\alpha_{A_{k}}\right) \frac{\left(\bar{\rho} Y_{A_{k}} \Delta z\right)_{\Sigma}}{\Delta z} Z_{k} \exp \left(-\frac{E_{k}}{R T}\right)$

The treatment of in-depth radiation is researched in the sensitivity analysis. In Gpyro, only 'one-way' radiation normal to the surface is calculated (i.e. radiation into the solid is calculated, whereas emission from other interior parts of the solid is not).

\section{TG/DTG Data and Kinetic Parameterization}

The kinetic parameters were obtained from an isoconversional method applied to LLDPE. The curves are constructed with 3 dynamics, $3.33 \times 10^{-2} \mathrm{~K} / \mathrm{s}^{1}, 8.33 \times 10^{-2} \mathrm{~K} / \mathrm{s}^{1}$ and $1.67 \times 10^{-1} \mathrm{~K} / \mathrm{s}^{1}$ using TGA data where the tests were performed in a nitrogen atmosphere. The method is a variation of the Ozawa, Flynn and Wall [7-8] (OFW finds a constant slope of $-E / R$ by plotting $\ln (\beta)$ versus $1 / T$ for each value of conversional coefficient, $\alpha$ ) based on the previous work of Friedman [9]). 
The results obtained for the activation energy are given in Fig. 1. The reaction mechanism $f(\alpha)$ was obtained through a method based on the DTG shape [10].

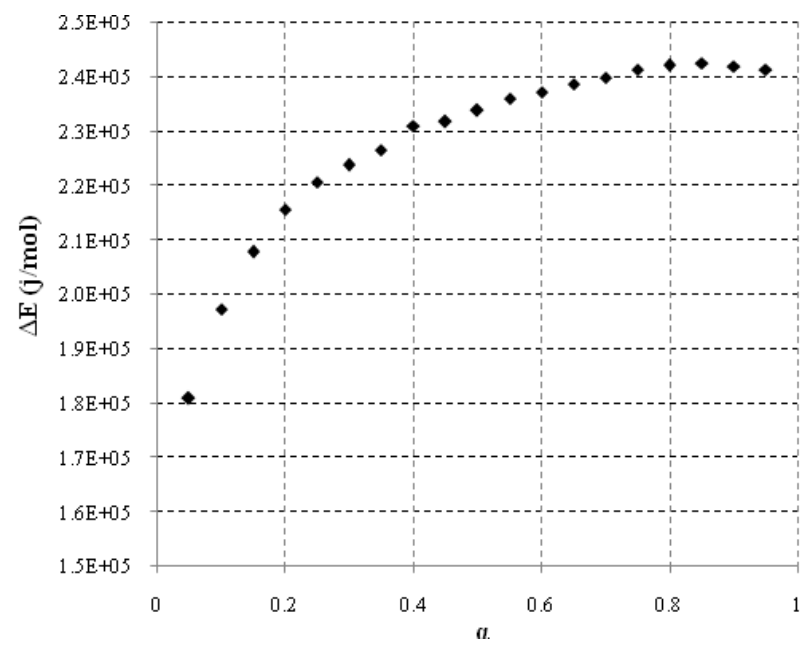

Fig. 1. Values of activation energy against different values of conversional coefficient.

Table 1. Results of DTG shape analysis.

\begin{tabular}{ccccc}
\hline $\begin{array}{c}\boldsymbol{\beta} \\
\left(\mathbf{K} \cdot \mathbf{s}^{-1}\right)\end{array}$ & $\begin{array}{c}\boldsymbol{T}_{\boldsymbol{m}} \\
(\mathbf{K})\end{array}$ & $\boldsymbol{\alpha}_{\boldsymbol{m}}$ & $\begin{array}{c}\text { FWHM } \\
(\mathbf{K})\end{array}$ & $\boldsymbol{T}_{\boldsymbol{i}}-\boldsymbol{T}_{\boldsymbol{f}}$ \\
\hline $1.67 \times 10^{-1}$ & 754.00 & 0.57 & 27 & diffuse - sharp \\
$8.33 \times 10^{-2}$ & 740.60 & 0.64 & 26 & diffuse - sharp \\
$3.33 \times 10^{-2}$ & 724.50 & 0.62 & 26 & diffuse - sharp \\
\hline
\end{tabular}

The analysis of parameters in Table 1 suggest that all of the tests have the same reaction mechanism, a deceleratory $\alpha$-t performance based on geometrical models of the 'contracting volume' type (R3) [10]. This model was parameterized by setting the heterogeneous reaction parameters $i_{\text {Kinetic model }}=8$ and $n=0.33$.

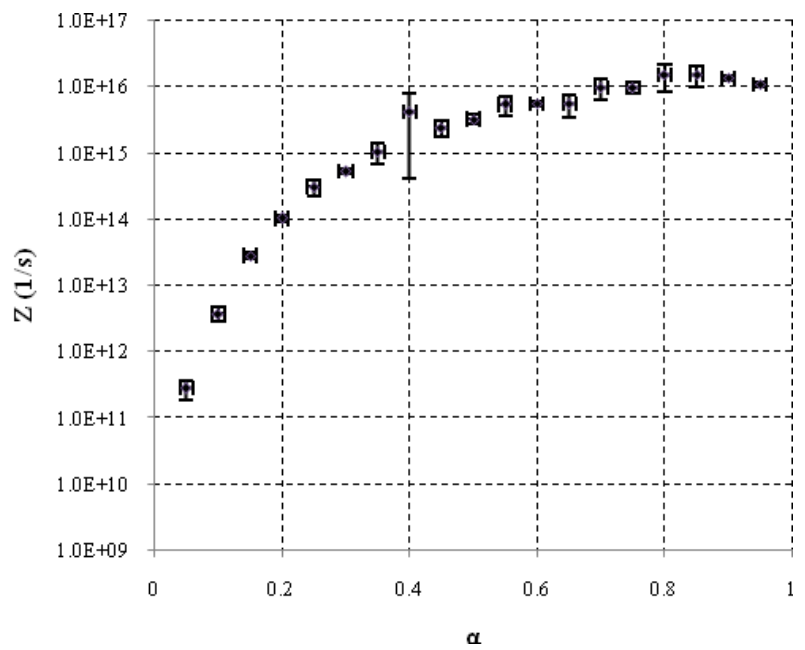

Fig. 2. Values of pre-exponential factor against different values of conversional coefficient. 
For this reaction model the $Z$ value was obtained as the mean value of three heating rates (Fig. 2). The performance of $E$ and $Z$ was defined by Galway et al. [11] as 'the kinetic compensation effect' (Fig. 3). The relationship was useful in determining a range of values for the optimization process.

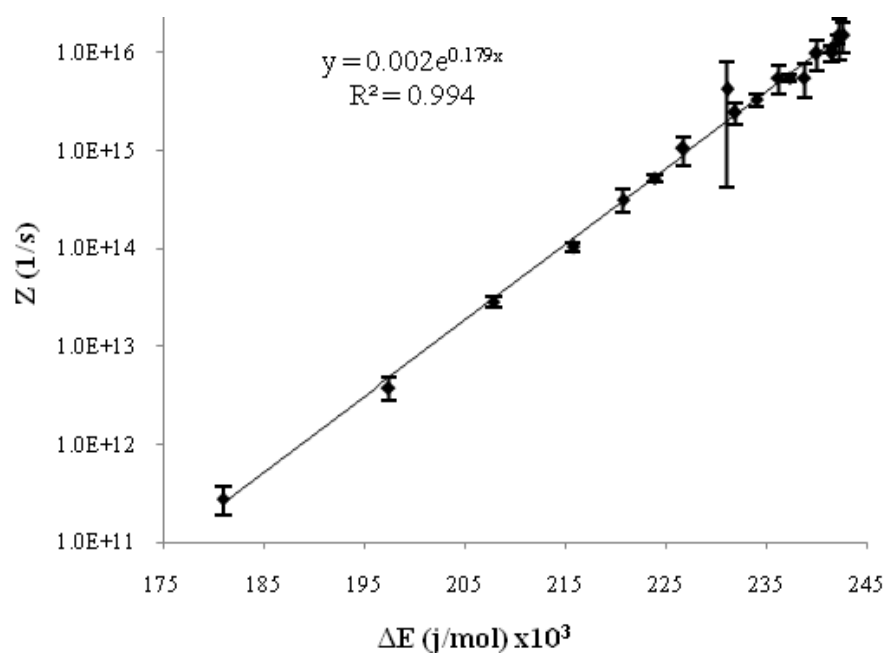

Fig. 3. Values of pre-exponential factor against activation energy for each conversional factor.

\section{Chemical Scheme}

A single chemical scheme based on a global one-step reaction was selected because the analysis of the TGA curves showed a continuous mass loss rate. The activation energy was between 180 and $240 \times 10^{3} \mathrm{~J} / \mathrm{mol}$. The physical interpretation of the increase of the chosen one during this study was done in Ref. [12]. The decomposition proceeds more slowly due to the absence of any nuclei in the reactant surface. With the formation of these ones, the reactant reaches an equilibrium state when the whole surface has been covered by a product film. In this equilibrium state, decomposition proceeds more rapidly. The TGA diagrams of all the heating rates are displayed in Fig. 4. The data from this test are summarized in Table 2.

Table 2. Features of TG/DTG data.

\begin{tabular}{ccccc}
\hline $\begin{array}{c}\boldsymbol{\beta} \\
\left(\mathbf{K} \cdot \mathbf{s}^{-\mathbf{1}}\right)\end{array}$ & $\begin{array}{c}\text { Mass } \\
(\mathbf{k g})\end{array}$ & $\begin{array}{c}\boldsymbol{T}_{\boldsymbol{i}} \\
(\mathbf{K})\end{array}$ & $\begin{array}{c}\boldsymbol{T}_{\boldsymbol{f}} \\
(\mathbf{K})\end{array}$ & $\begin{array}{c}\boldsymbol{d t g}_{\text {peak }} \\
(\mathbf{\%} / \mathbf{s})\end{array}$ \\
\hline $1.67 \times 10^{-1}$ & $9.92 \times 10^{-6}$ & 674.15 & 776.15 & 0.53 \\
$8.33 \times 10^{-2}$ & $8.67 \times 10^{-6}$ & 657.15 & 763.15 & 0.27 \\
$3.33 \times 10^{-2}$ & $9.74 \times 10^{-6}$ & 634.15 & 735.15 & 0.11 \\
\hline
\end{tabular}

Figure 4 shows that a rise in heating implies a shift to higher temperatures on TGA diagram. The mass loss was similar for each $\beta$, but the temperature at the beginning of decomposition was not. Note that the peak of DTG plot was directly related to $\beta$. 


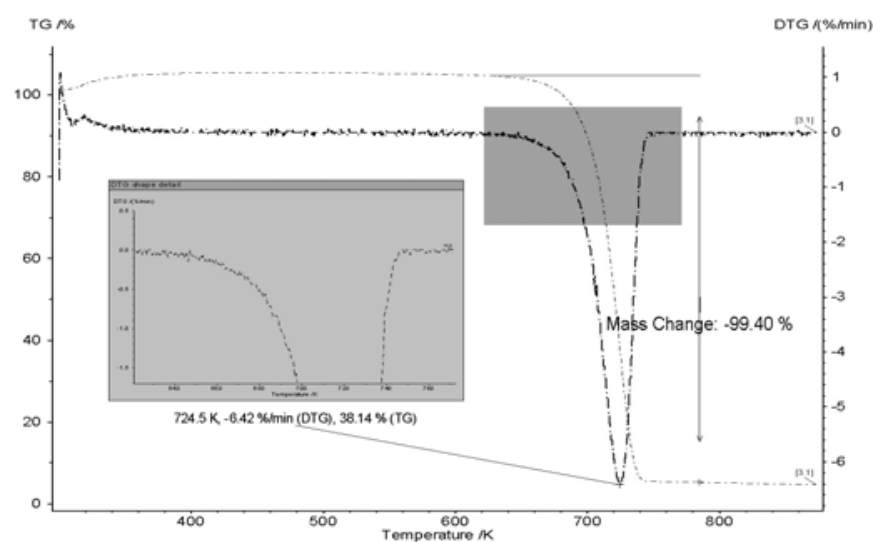

(a)

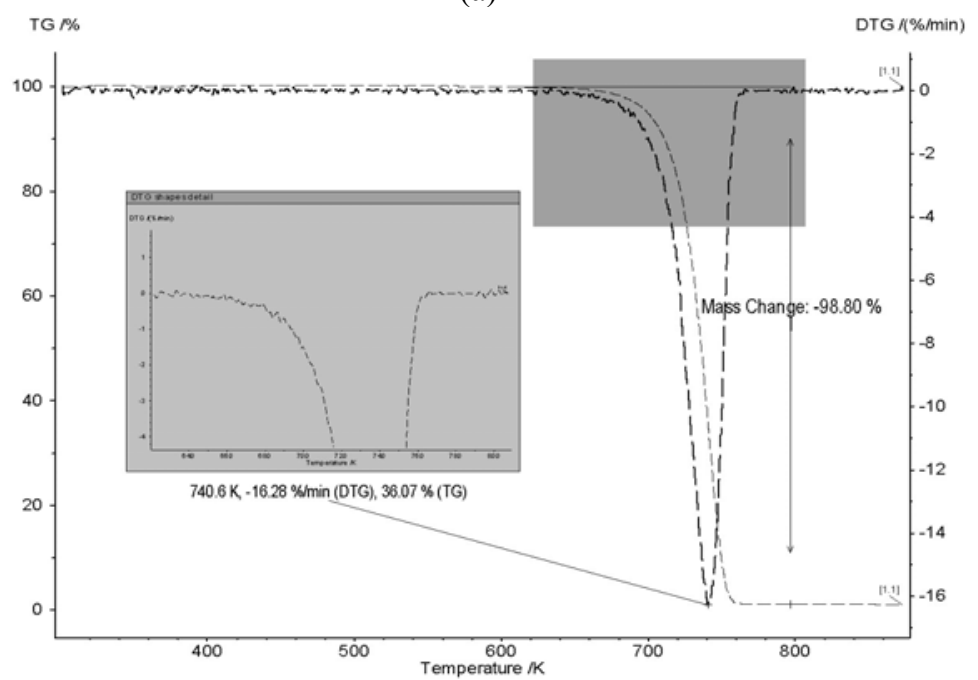

(b)

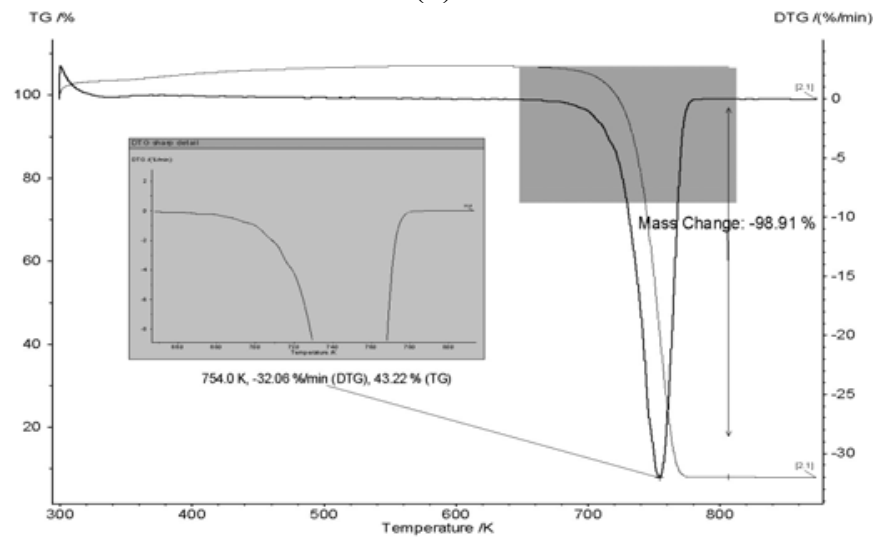

(c)

Fig. 4. TG/DTG at: (a) $3.33 \times 10^{-2} \mathrm{~K} \cdot \mathrm{s}^{-1}$; (b) $8.33 \times 10^{-2} \mathrm{~K} \cdot \mathrm{s}^{-1}$; (c) $1.67 \times 10^{-1} \mathrm{~K} \cdot \mathrm{s}^{-1}$.

\section{Decomposition Energy}

The STA test includes both TGA and DSC data. The reaction enthalpies play an important role in modelling the virtual material. Table 3 summarizes the DSC data and the DSC diagram at maximum heating rate is shown in Fig. 5. 
Table 3. Features DSC data.

\begin{tabular}{cccc}
\hline $\begin{array}{c}\boldsymbol{\beta} \\
\left(\mathbf{K}^{-\mathbf{1}}\right)\end{array}$ & $\begin{array}{c}\Delta \boldsymbol{h}_{\boldsymbol{d}} \\
(\mathbf{J} / \mathbf{k g})\end{array}$ & $\begin{array}{c}\boldsymbol{d s \boldsymbol { c } _ { \text { peak } }} \\
\mathbf{( W / k g )}\end{array}$ & $\begin{array}{c}\boldsymbol{T}_{\text {peak }} \\
(\mathbf{K})\end{array}$ \\
\hline $1.67 \times 10^{-1}$ & 751200 & 3400 & 753.60 \\
$8.33 \times 10^{-2}$ & 1595000 & 2200 & 739.00 \\
$3.33 \times 10^{-2}$ & 2950000 & 2300 & 721.40 \\
\hline
\end{tabular}

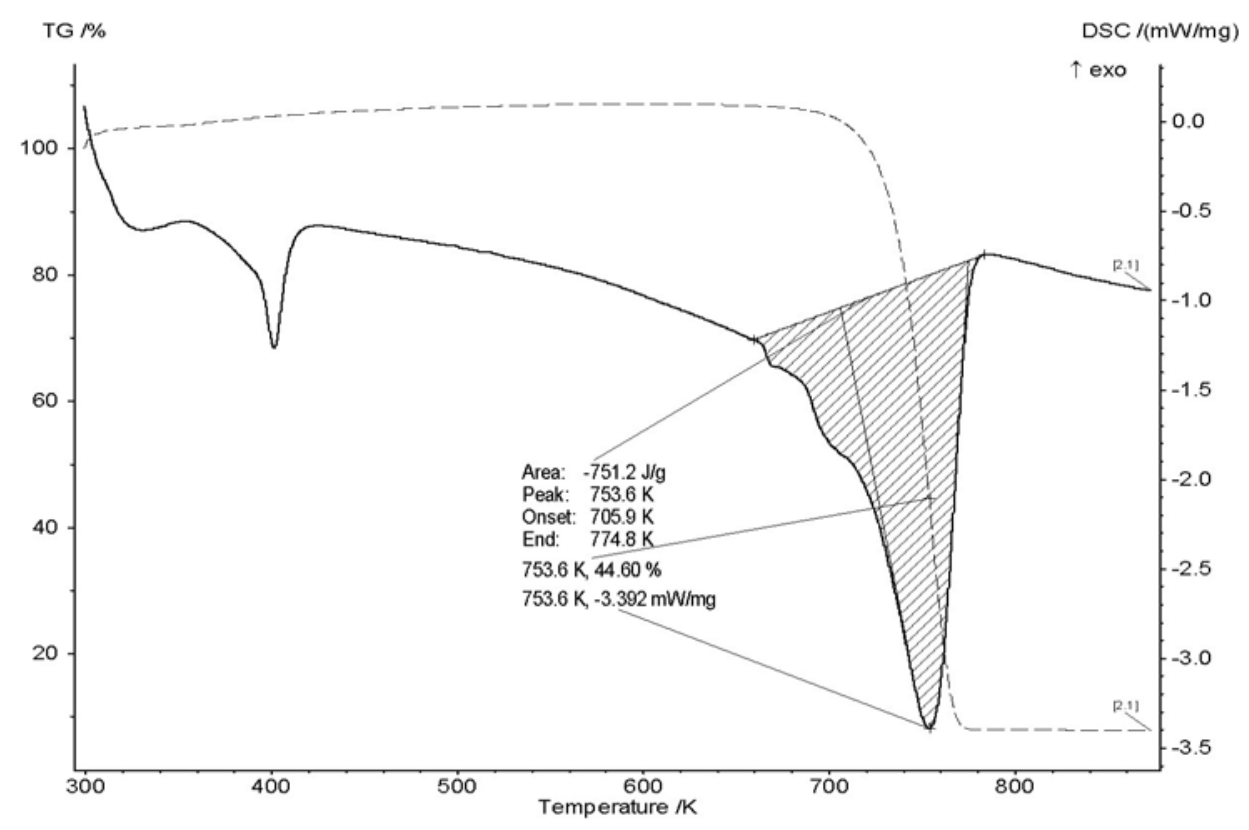

Fig. 5. DSC at $1.67 \times 10^{-1} \mathrm{~K} \cdot \mathrm{s}^{-1}$.

The decrease of decomposition enthalpies with the heating rate is an unexpected result and may result from catalytic processes. Similar to the DTG curves, the temperature of decomposition shifts to higher temperatures.

\section{Reaction Parameterization}

A simple one-step reaction was chosen for the virtual chemical scheme. Decomposition of LLDPE is a complex process but it is possible to check the options of this methodology to model a complex performance. The process modeled is shown in Fig. 6.

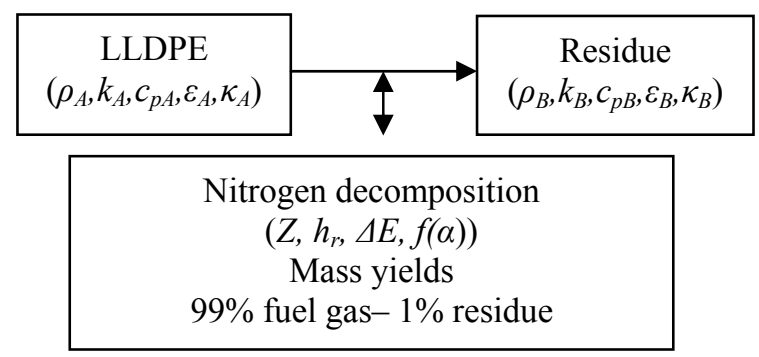

Fig. 6. Decomposition scheme. 
Table 4. Range of optimization values.

\begin{tabular}{llcc}
\hline Parameter & Units & Minimum value & Maximum value \\
\hline$Z$ (log scale $)$ & $\mathrm{s}^{-1}$ & 11 & 14 \\
$E$ & $\mathrm{~J} / \mathrm{mol}$ & 175000 & 210000 \\
$\Delta h_{d}$ & $\mathrm{~J} / \mathrm{kg}$ & 500000 & 784500 \\
$k_{A}$ & $\mathrm{~W} / \mathrm{m} \cdot \mathrm{K}$ & 0.15 & 0.42 \\
$\varepsilon_{A}$ & - & 0.8 & 0.95 \\
$c_{p A}$ & $\mathrm{~J} / \mathrm{kg} \cdot \mathrm{K}$ & 1500 & 2100 \\
$\kappa_{A}$ & $\mathrm{~m}^{-1}$ & 1000 & 50000 \\
$k_{B}$ & $\mathrm{~W} / \mathrm{m} \cdot \mathrm{K}$ & 0.05 & 0.2 \\
$\varepsilon_{B}$ & - & 0.8 & 0.95 \\
$c_{p B}$ & $\mathrm{~J} / \mathrm{kg} \cdot \mathrm{K}$ & 500 & 1000 \\
$\kappa_{B}$ & $\mathrm{~m}^{-1}$ & 1000 & 50000 \\
\hline
\end{tabular}

The activation energy was selected from the lower values of the conversional coefficient because the first step of decomposition was described in nitrogen without synergetic performance. The parameters $\rho$ and $f(\alpha)$ were fixed but the other parameters were chosen for the optimization process. The range of values id given in Table 4.

The values of specific heat, thermal conductivity, and emissivity were obtained from Refs. $[5,13,14]$. The value of $\kappa$ was selected to obtain a range of in-depth thermal penetrations of $0.02-1 \times 10^{-3} \mathrm{~m}$. The value of decomposition enthalpy at $1.67 \times 10^{-1} \mathrm{~K} / \mathrm{s}^{1}$ was chosen as a limited value of enthalpy of global decomposition because the process to model had higher values of heating rate. The activation energy range was $175-210 \times 10^{3} \mathrm{~J} / \mathrm{mol}$ due to the accuracy of the isoconversional method [15].

\section{Cone Calorimeter Parameterization}

The setup of the Cone Calorimeter model in Gpyro is a one-dimensional test. The cell size was $10^{-4} \mathrm{~m}$. The irradiance of the flame on the surface was taken as $15 \mathrm{~kW} / \mathrm{m}^{2}$ [16]. The solver for gas energies was turned off (SOLVE_GAS_ENERGY =.FALSE.).

\section{Cone Calorimeter Results}

The results obtained at different irradiance levels are shown in Fig. 7.

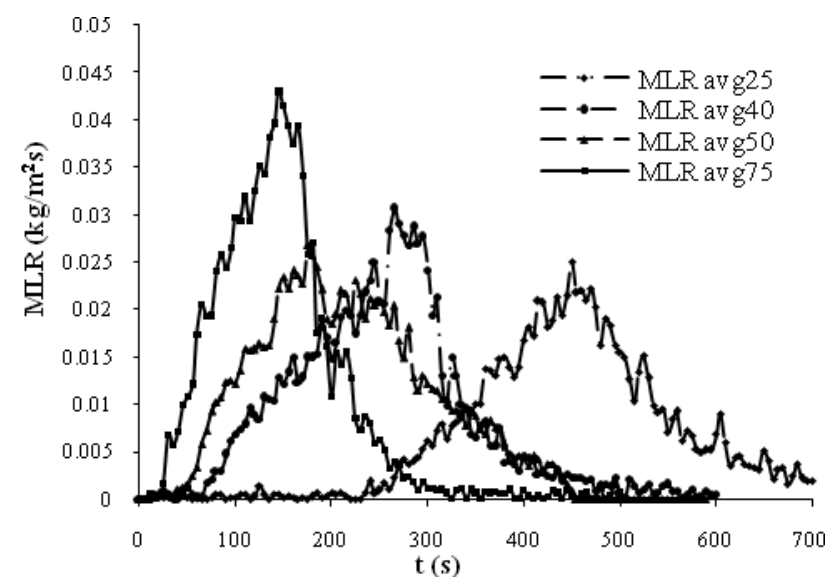

Fig. 7. MLR mean values obtained from cone calorimeter tests.

This research deals with modelling the performance at each flux level from one set of parameters because the fire models will need a virtual material with a good performance at a wide range of heat fluxes similar to the complex field of fluxes in a fire scenario. Table 5 shows a summary of cone calorimeter results. 
Table 5. Summary of the cone calorimeter data

\begin{tabular}{|cccc|}
\hline $\begin{array}{c}\text { Heat flux } \\
\left(\mathbf{k W} / \mathbf{m}^{2}\right)\end{array}$ & $\begin{array}{c}\boldsymbol{t}_{\text {ignition }} \\
(\mathbf{s})\end{array}$ & $\begin{array}{c}\boldsymbol{M L R}_{\text {peak }} \\
\left(\mathbf{k g} / \mathbf{m}^{2} \cdot \mathbf{s}\right)\end{array}$ & $\begin{array}{c}\boldsymbol{t}_{\text {peak }} \\
(\mathbf{s})\end{array}$ \\
\hline $25 \pm 2$ & $242 \pm 7$ & $2.5 \times 10^{-2} \pm 8.8 \times 10^{-3}$ & $450 \pm 24$ \\
$40 \pm 2$ & $63 \pm 3$ & $3.0 \times 10^{-2} \pm 2.6 \times 10^{-3}$ & $265 \pm 1$ \\
$50 \pm 2$ & $39 \pm 2$ & $2.7 \times 10^{-2} \pm 1.3 \times 10^{-2}$ & $175 \pm 25$ \\
$75 \pm 2$ & $20 \pm 1$ & $4.3 \times 10^{-2} \pm 1.9 \times 10^{-3}$ & $145 \pm 13$ \\
\hline
\end{tabular}

The analysis of material performance showed that the MLR repeatability was adequate at $9 \%$ at $40 \mathrm{~kW} / \mathrm{m}^{2}$ and $4 \%$ at $75 \mathrm{~kW} / \mathrm{m}^{2}$, but not at $35 \%$ for $25 \mathrm{~kW} / \mathrm{m}^{2}$ and $48 \%$ at $50 \mathrm{~kW} / \mathrm{m}^{2}$. However, the ignition time was sufficiently repeatable at all flux levels. The time to peak MLR showed the same performance as peak MLR. This observation was taken into account when comparing the final simulated results.

\section{Model Results}

The results present a direct simulation in Gpyro by a model set-up obtained from the analysis of the STA data. The values of parameters used were obtained from the STA diagrams $(Z, \Delta E, f(\alpha), v$ 's and enthalpies) analysis, direct measurements (e.g. density), and literature values. The values of these parameters are displayed at the end of the results discussion so that they can be compared with the optimized values. Figure 8 displays the MLR results against direct simulated results.

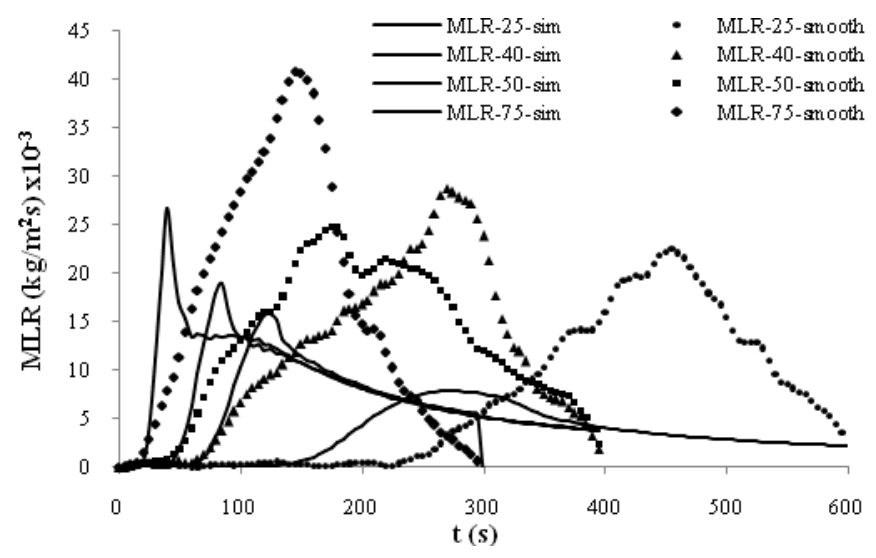

Fig. 8. MLR curves obtained from direct modelling of cone calorimeter tests in Gpyro.

The real data was smoothed as an average of four points to enable a clear discussion of results. So $M L R i=$ $[(M L R i-2+M L R i+2) / 2+M L R i-1+M L R i+M L R i+1] / 4$, where MLRi is MLR value at time $t_{i}$. For the second and $N-1$ terms (where $N$ is the number of intervals between $t=0$ and $\left.t=t_{\text {end }}\right) M L R i=[(M L R i-1+$ $M L R i+1) / 2+M L R i] / 2$. For the first and last values, there was no smoothing.

Table 6. Summary of the direct modelling of the cone calorimeter; simulated vs. smooth

\begin{tabular}{|c|c|c|c|}
\hline $\begin{array}{l}\text { Heat flux } \\
\left(\mathrm{kW} / \mathbf{m}^{2}\right)\end{array}$ & $\begin{array}{c}\boldsymbol{t}_{\text {ignition }} \\
(\mathbf{s})\end{array}$ & $\begin{array}{r}M L R_{\text {peak }} \\
\left(\mathrm{kg} / \mathrm{m}^{2} \cdot \mathrm{s}\right) \\
\end{array}$ & $\begin{array}{c}t_{\text {peak }} \\
(\mathrm{s})\end{array}$ \\
\hline 25 & $155-240$ & $7.9 \times 10^{-3}-2.3 \times 10^{-2}$ & $275-455$ \\
\hline 40 & $65-65$ & $1.6 \times 10^{-2}-2.9 \times 10^{-2}$ & $125-270$ \\
\hline 50 & $40-40$ & $1.9 \times 10^{-2}-2.5 \times 10^{-2}$ & $85-180$ \\
\hline 75 & $20-20$ & $2.6 \times 10^{-2}-4.1 \times 10^{-2}$ & $40-145$ \\
\hline
\end{tabular}

The ignition times were good except at $25 \mathrm{~kW} / \mathrm{m}^{2}$ where the relative error was $55 \%$. The $M L R_{\text {peak }}$ variability was larger than the variability of ignition times - the relative errors were $191 \%$ at $25 \mathrm{~kW} / \mathrm{m}^{2}$, $81 \%$ at $40 \mathrm{~kW} / \mathrm{m}^{2}, 32 \%$ at $50 \mathrm{~kW} / \mathrm{m}^{2}$ and $58 \%$ at $75 \mathrm{~kW} / \mathrm{m}^{2}$. With regard to time to peak, the results show relative errors of $65 \%$ at $25 \mathrm{~kW} / \mathrm{m}^{2}, 116 \%$ at $40 \mathrm{~kW} / \mathrm{m}^{2}, 112 \%$ at $50 \mathrm{~kW} / \mathrm{m}^{2}$ and $262 \%$ at $75 \mathrm{~kW} / \mathrm{m}^{2}$. 
Optimized Model Results

Figure 9 displays the results for the optimized model results.

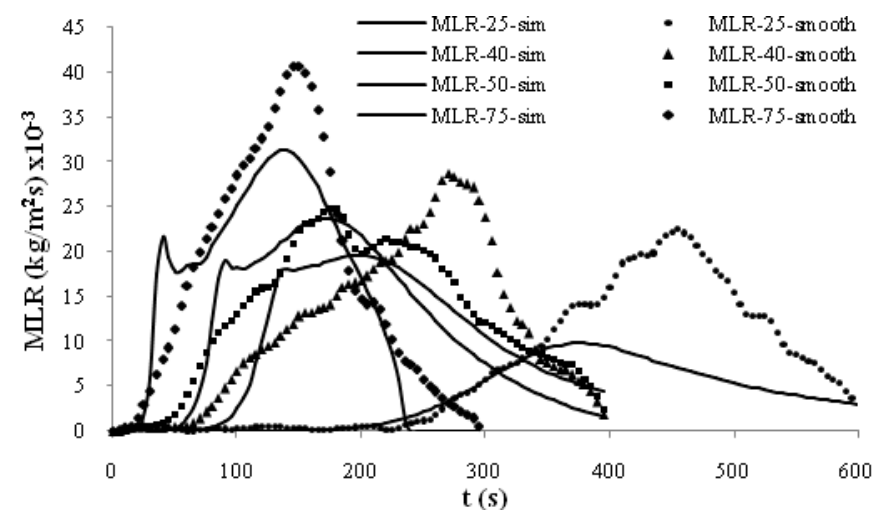

Fig. 9. MLR curves obtained from the best simulation of cone calorimeter tests in Gpyro at the $40^{\text {th }}$ generation.

Table 7. Summary of the optimized modelling of the cone calorimeter; simulated vs. smooth

\begin{tabular}{cccc}
\hline $\begin{array}{c}\text { Heat flux } \\
\left(\mathbf{k W} / \mathbf{m}^{\mathbf{2}}\right)\end{array}$ & $\begin{array}{c}\boldsymbol{t}_{\text {ignition }} \\
(\mathbf{s})\end{array}$ & $\begin{array}{c}\boldsymbol{M L R}_{\text {peak }} \\
\left(\mathbf{k g} / \mathbf{m}^{2} \cdot \mathbf{s}\right)\end{array}$ & $\begin{array}{c}\boldsymbol{t}_{\text {peak }} \\
(\mathbf{s})\end{array}$ \\
\hline 25 & $215-240$ & $9.8 \times 10^{-3}-2.3 \times 10^{-2}$ & $375-455$ \\
40 & $85-65$ & $2.0 \times 10^{-2}-2.9 \times 10^{-2}$ & $200-270$ \\
50 & $55-40$ & $2.4 \times 10^{-2}-2.5 \times 10^{-2}$ & $175-180$ \\
75 & $20-20$ & $3.1 \times 10^{-2}-4.1 \times 10^{-2}$ & $140-145$ \\
\hline
\end{tabular}

Note that the results displayed above show a good performance at an irradiance level of $50 \mathrm{~kW} / \mathrm{m}^{2}$. For all the irradiance levels the time to ignition was acceptable - the relative errors were between $0 \%$ at $75 \mathrm{~kW} / \mathrm{m}^{2}$ and $27 \%$ at $50 \mathrm{~kW} / \mathrm{m}^{2}$. The $M L R_{\text {peak }}$ variability was larger than the variability of ignition times - the relative errors were $135 \%$ at $25 \mathrm{~kW} / \mathrm{m}^{2}, 45 \%$ at $40 \mathrm{~kW} / \mathrm{m}^{2}, 4 \%$ at $50 \mathrm{~kW} / \mathrm{m}^{2}$ and $32 \%$ at $75 \mathrm{~kW} / \mathrm{m}^{2}$. About of time to peak the results shows relative errors of $21 \%$ at $25 \mathrm{~kW} / \mathrm{m}^{2}, 35 \%$ at $40 \mathrm{~kW} / \mathrm{m}^{2}, 3 \%$ at $50 \mathrm{~kW} / \mathrm{m}^{2}$ and $4 \%$ at $75 \mathrm{~kW} / \mathrm{m}^{2}$.

Parameter Comparison

Table 8 displays the results of the STA, literature and optimized values.

Table 8. Comparison of parameters for the model.

\begin{tabular}{llccc}
\hline Parameter & Units & Initial & Optimized & Difference \\
\hline$Z$ & $\mathrm{~s}^{-1}$ & $2.8 \times 10^{12}$ & $1.72 \times 10^{12}$ & $-39 \%$ \\
$\Delta E$ & $\mathrm{~J} / \mathrm{mol}$ & 185000 & 195000 & $+5 \%$ \\
$\Delta h_{d}$ & $\mathrm{~J} / \mathrm{kg}$ & 784500 & 690000 & $-12 \%$ \\
$k_{A}$ & $\mathrm{~W} / \mathrm{m} \cdot \mathrm{K}$ & 0.35 & 0.31 & $-13 \%$ \\
$\varepsilon_{A}$ & - & 0.88 & 0.85 & $-3 \%$ \\
$c_{p A}$ & $\mathrm{~J} / \mathrm{kg} \cdot \mathrm{K}$ & 1916 & 1880 & $-2 \%$ \\
$\kappa_{A}$ & $\mathrm{~m}^{-1}$ & 3000 & 28200 & $+840 \%$ \\
$k_{B}$ & $\mathrm{~W} / \mathrm{m} \cdot \mathrm{K}$ & 0.1 & 0.19 & $+90 \%$ \\
$\varepsilon_{B}$ & - & 0.9 & 0.87 & $-3 \%$ \\
$c_{p B}$ & $\mathrm{~J} / \mathrm{kg} \cdot \mathrm{K}$ & 800 & 747 & $-7 \%$ \\
$\kappa_{B}$ & $\mathrm{~m}^{-1}$ & 3000 & 29400 & $+880 \%$ \\
\hline
\end{tabular}


The fixed parameters were $\rho_{A}=950 \mathrm{~kg} \cdot \mathrm{m}^{-3}, \rho_{B}=9.50 \mathrm{~kg} \cdot \mathrm{m}^{-3}, T_{\text {melt }}=395 \mathrm{~K}, T_{\text {ambient }}=301 \mathrm{~K}$ and convective heat transfer coefficient, $h_{c}=13 \mathrm{~W} \cdot \mathrm{m}^{-2} \cdot \mathrm{K}^{-1}$.

Note that the optimization process obtained the best results for large values of the absorption coefficient which means the optimization is more effective when the radiation influence become important at the surface of the material - i.e. pure conduction into the solid. However the parameter values obtained were close to the initial parameters because the range chosen was limited to obtain values with a physical meaning [17].

\section{CONCLUSION}

The methodology enables a usable set of parameters for modeling pyrolysis in fire computer models to be obtained with values close to those of the real properties (Table 8). It can be used to predict the performance of the material at different irradiance levels similar to real fire scenarios. However the results showed (Table 6) that the real properties of materials should not be directly input as model parameters.

A derived conclusion of this work is that a physical interpretation of the decomposition process [12] can offer an alternative meaning to the variation of activation energies during the mass loss processes and the use of simplified single step chemical schemes. The use of a one-step process allows for the modeling of a complex process such as the decomposition of LLDPE.

A thermo-oxidative pyrolysis model with exothermic values of enthalpy could explain the outlier value for the peak at $25 \mathrm{~kW} / \mathrm{m}^{2}$ because the large amount of energy released by polyethylene enables a high reaction rate.

\section{ACKNOWLEDGEMENTS}

The authors would like to thank the department for R\&D of the Grupo General Cable Sistemas, S.A. for LLDPE samples which belong to the project "Modelado Matemático Del Comportamiento Al Fuego De Cables" jointly developed by Grupo General Cable Sistemas, S.A. and GIDAI Group of the University of Cantabria. And we would also like to thank the Subsidy TRA2010-19006 awarded for the project "Modelado Matematico De La Combustion De Los Materiales Presentes En Los Trenes De Pasajeros De Alta Velocidad" by the Ministry of Science and Innovation (Spanish Government).

\section{REFERENCES}

[1] Quintiere, J.Q., "A Semi-Quantitative Model for the Burning Rate of Solid Materials," National Institute of Standards and Technology Report NISTIR 4840, Gaithersburg, MD, 1992, 42 p.

[2] Moghtaderi, B., Novozhilov, V., Fletcher, D. and Kent, J.H., (1997) An Integral Model for the Transient Pyrolysis of Solid Materials, Fire and Materials, 21: 7-16. http://dx.doi.org/10.1002/(SICI)1099-1018(199701)21:1<7::AID-FAM588>3.0.CO;2-T

[3] Di Blasi, C., (1993) Modeling and Simulation of Combustion Processes of Charring and NonCharring Solid Fuels, Progress in Energy and Combustion Science 19: 71-104. http://dx.doi.org/10.1016/0360-1285(93)90022-7

[4] McGrattan, K., Hostikka, S., Floyd, J., Baum, H. and Rehm, R. "Fire Dynamics Simulator (Version 5), Technical Reference Guide, Volume 1: Mathematical Model”, National Institute of Standards and Technology Special Publication 1018-5, Gaithersburg, MD, 2009, 124 p.

[5] Lautenberger, C., "A Generalized Pyrolysis Model for Combustible Solids," Ph.D Dissertation, Department of Mechanical Engineering, University of California, Berkeley, 2007.

[6] ISO 5660-1:2002 Reaction-to-fire tests - Heat release, smoke production and mass loss rate (cone calorimeter method). International Organization for Standardization, 2002.

[7] Ozawa, T. (1970), Kinetic analysis of derivative curves in thermal analysis, Journal of Thermal Analysis and Calorimetry 2, 3: 301-324. http://dx.doi.org/10.1007/BF01911411

[8] Ozawa, T., (1992) Estimation of activation energy by isoconversion methods, Thermochimica Acta, 203: 159 - 165. http://dx.doi.org/10.1016/0040-6031(92)85192-X 
[9] Friedman, H., (1964) Kinetics of thermal degradation of char-forming plastics from thermogravimetry, Application to a phenolic plastic. Journal of Polymeric Sciences Part C, 6: 183195. http://dx.doi.org/10.1002/polc.5070060121

[10] Haixiang, C., Naian, L. and Weitao, Z., (2010) Critical study on the identification of reaction mechanism by the shape of TG/DTG curves, Solid State Sciences, 12: 455-460. http://dx.doi.org/10.1016/j.solidstatesciences.2009.12.007

[11] Galwey, A.K. and Brown, M.E., Thermal Decomposition of Ionic Solids, Elsevier, Amsterdam, 1999, p. 165.

[12] L'vov, B.V., (2001) The Physical approach to the interpretation of the kinetics mechanisms of thermal decomposition of solids: the state of the art. Thermochimica Acta 373, 2: 97-124. http://dx.doi.org/10.1016/S0040-6031(01)00507-X

[13] Brandrup, J., Immergut, E.H. and Grulke, E.A., Polymer Handbook, Wiley-Interscience; $4^{\text {th }}$ edition (1999).

[14] Babrauskas, V., Ignition Handbook. Interscience Communications Ltd., London, UK, (2003).

[15] Keuleers, R.R., Janssens, J.F. and Desseyn, H.O., (2002) Comparison of some methods for activation energy determination of thermal decomposition reactions by thermogravimetry, Thermochimica Acta 385: 127-142. http://dx.doi.org/10.1016/S0040-6031(01)00720-1

[16] Stoliarov, S.I., Crowley, S., Lyon, R.E. and Linteris. G.T., (2009) Prediction of the Burning Rates of Non-Charring Polymers, Combustion and Flame, 156: 1068-1083. http://dx.doi.org/10.1016/j.combustflame.2008.11.010

[17] Webster, R., Lázaro, M., Alvear, D., Capote, J.A. and Trouvé, A., "Limitations in current parameter estimation techniques for pyrolysis modeling". Proceedings of the $6^{\text {th }}$ International Seminar on Fire and Explosion Hazards. University of Leeds (UK), 2010. 